\title{
Recommendations to improve the insurance coverage for physiotherapy services in Iran A multi- criteria decision making approach
}

Saeed Shahabi ( $\nabla$ saeedshahabi1@gmail.com )

Shiraz University of Medical Sciences

\section{Seyed Taghi Heydari}

Shiraz University of Medical Sciences

Kamran Bagheri Lankarani

Shiraz University of Medical Sciences

Leila Zarei

Shiraz University of Medical Sciences

\section{Research article}

Keywords: insurance coverage, physiotherapy, health policy, rehabilitation, analytical hierarchy process

Posted Date: March 20th, 2020

DOI: https://doi.org/10.21203/rs.3.rs-18069/v1

License: (c) (i) This work is licensed under a Creative Commons Attribution 4.0 International License. Read Full License 


\section{Abstract}

Background High rate of traffic injuries, climate changes, natural disasters, aging, and chronic diseases have been resulted in a considerable demand for receiving physiotherapy in Iran. However, there are various complications in utilization of physiotherapy services, especially poor insurance coverage. This study investigated and prioritized potential policy recommendations to improve the insurance coverage for physiotherapy services in Iran.

Methods The present project was carried out using mix-method (qualitative-quantitative) approach in Iran. In the first phase, a qualitative study was conducted to find the policy recommendations and in the second phase, obtained policy recommendations were prioritized based on the effectiveness, acceptability, cost, fairness, feasibility, and time using Analytical Hierarchy Process (AHP).

Results In the first phase, 30 semi-structured interviews with health policy-makers, health insurers, faculty members, rehabilitation experts, and physiotherapists were conducted. Several policy recommendations were proposed by participants. Following the second phase, prioritized recommendations were provided to promote stewardship (e.g. informing the policy-makers about physiotherapy services), collection of funds (e.g. value-added tax on luxury goods and services), pooling of funds (e.g. moving the allocated resources to insurance (third party) mechanism), purchasing (e.g. using strategic purchasing), and benefit package (e.g. considering the preventive interventions) as main components of insurance coverage.

Conclusion The findings of this study will be provided a favorable ground to improve the insurance coverage for physiotherapy services in Iran, and decision- and policy-makers can place these recommendations at their agenda settings in the health sector to protect the health status of population, especially disabled groups.

\section{Background}

Approximately $15 \%$ of people worldwide experience disability, which due to the enhancing the prevalence of chronic diseases, the aging population, traffic injuries, and rate of survivors from trauma, it is predicted to get worse in the future years [1]. In a study in 2019, it was showed that, the burden of musculoskeletal (MSK) disorders increased significantly over the past decades, and MSK disorders are the second cause of years lived with disability (YLDs) [2]. In addition, the incidence and prevalence of neurological disorders such as tetanus, meningitis, encephalitis, stroke, traumatic brain injury, and spinal cord injury, has been increased in recent years, which these disorders remain the main group cause of disability-adjusted life years (DALYs) [3]. Low-Back Pain (LBP), neck pain, Osteoarthritis (OA), and Arthritis Rheumatoid (AR) are the leading MSK disorders, which show a high burden especially in Eastern Mediterranean Region (EMR) including Iran [4]. Therefore, in accordance with the current global trends, the need for physical rehabilitation services including physiotherapy interventions is increasing [5].

Because of the high rate of traffic injuries (head trauma, fractures, and spinal cord injuries), climate changes, natural disasters, aging, and chronic diseases, demand for receiving physiotherapy also is considerable in Iran [6-8]. Therefore, appropriate financing and providing of these services are necessary. 
However, physiotherapy often is considered as luxury and tertiary services in Iranian health care system [9]. Most of the physiotherapy services are provided by private centers, and due to insufficient insurance coverage, out-of-pocket (OOP) payments are the leading reimbursement mechanism. As a result, a major proportion of households are suffering from catastrophic expenditures (CEs) [10].

The World Health Organization (WHO) has introduced the rehabilitation services as one of the main dimensions of the universal health coverage (UHC) [11]. Recently, the "Global Disability Action Plan 20142021" was initiated by WHO in response to the increased demands for these interventions[1]. In addition, to improve the accessibility of rehabilitation services, such as physiotherapy, "Rehabilitation 2030: a call for action" was initiated [12]. Integrating the rehabilitation services in health care systems and improving the insurance coverage for rehabilitation services, are the leading goals of this guidance. However, in many countries (especially undeveloped and developing countries) no specific funding is determined to rehabilitation sector[13].

The aim of UHC for all population to receive the interventions they need at a cost level that protecting themselves from financial hardship[14]. Consequently, financing is one of the key functions in health care systems including physiotherapy services. To secure the financial protection, various strategies, such as pre-payment and pooling, are recommended [15]. Indeed, evidence are believed that insurance mechanism (as a pre-payment approach) can facilitate the risk-sharing and risk-pooling, and finally, reduce the direct payments[16]. Therefore, moving to insurance mechanism is the inevitable option to financing the health care services such as physiotherapy. Although the preventive, curative, and rehabilitative effects of physiotherapy interventions were confirmed by the relevant evidence [17-20], their insurance coverage still is weak in Iran like many other countries [10]. Nowadays, fragmentation in financing and providing of physiotherapy services, like other Iranian health sub-systems, leads to duplication and unnecessary waste. In fact, different actors and stakeholders (including Ministry of Health, Social Security Organization (SSO), Iran Health Insurance Organization (IHIO), Armed Forces Social Security Organization (AFSSO), Hilal Ahmar (in English Red Crescent), State Welfare Organization of Iran, Iranian Physiotherapy Association, and etc.) are involved in this process $[9,21]$.

In response to aforementioned situation, we decided to conduct a comprehensive study to find policy recommendations to improve the insurance coverage for physiotherapy services in Iran. It can also apply as a case study for insurance and health care systems in other countries.

\section{Methods}

The present project was carried out using mix-method (qualitative-quantitative) approach in Iran. An overview of the study is outlined in Fig. 1.

Firstly, a qualitative study was conducted to obtain the recommendations to improve the insurance coverage for physiotherapy services in Iran. The face-to-face semi-structured interviews were conducted by S.Sh (a male PhD and Health policy-maker with experience of rehabilitation researches) in Tehran, the capital of Iran. Further, the Skype and telephone interviews were used for samples that lived in other areas. 
The participants were recruited using purposive and snowball sampling, and the sampling was continued until the data saturation is achieved. The first researcher was contacted (by phone or e-mail) each participant to set a mutually date and time for interview session. The study population included health policy-makers, health insurers, faculty members, rehabilitation experts, and physiotherapists (Table 1). Interview guides consisted of open-ended questions which developed based on the conceptual framework components (stewardship, collection of funds, pooling of funds, purchasing, and benefit package) (Supplemental Fig. 1) [16]. The interviews were recorded digitally and performed in a convenient and quiet room. Transcribed verbatim was done after each session and all of the participants be allowed to review their interview transcripts, and if required, they had the opportunity to correct it. In addition, peer debriefing, triangulation, and prolonged engagement of the first author were considered to enhance the rigor and trustworthiness. To secure that the participants remained anonymous, ID numbers were used through the transcription. This phase was performed from July to November 2019.

Table 1

\begin{tabular}{|ll|}
\hline Composition of expert team \\
\hline Participants & No. \\
\hline Health policy-maker & 6 \\
\hline Health insurer & 4 \\
\hline Faculty members & 7 \\
\hline Rehabilitation expert & 5 \\
\hline Physiotherapist & 8 \\
\hline
\end{tabular}

Secondly, to prioritize the obtained recommendations, the Analytical Hierarchy Process (AHP) introduced by Dr. Saaty process in 1977, was used [22]. AHP is a multi-criteria decision making (MCDM) approach using pairwise comparisons to compare available alternatives with the relevant criteria and determine the best alternatives (Fig. 2). Based on the WHO priority-setting guideline, we considered effectiveness, acceptability, cost, fairness, feasibility, and time as the relevant criteria [23]. Relative importance of the six criteria achieved from eleven experts (by S.Sh), either via e-mail or at their workplace. There are no pre-defined principals to ascertain the adequate sample size of experts for AHP study. In fact, one expert viewpoint may suffice, in accordance with the aims of the study, unless several experts from different backgrounds are necessary, and so, various experts are needed if they are accessible[24]. Based on the pairwise comparison matrix, experts were asked to express their viewpoints using Saaty's nine point rating scale (Table 2). Then, the final value for each pairwise comparison was calculated based on the geometric logarithmic mean. These weighted values revealed the relative importance of each of six criteria, and these values were used to determine the relative preferences for the recommendations. Furthermore, the inconsistency of the experts' viewpoints was calculated for each pairwise comparison. In accordance the evidence, an inconsistency index less than or equal to $0.1(\mathrm{I} . \mathrm{R}=<0.10)$ can be accepted[25]. AHP analysis was conducted using Expert Choice 11 software (Arlington, Virginia, USA). 
Table 2

Saaty's pairwise comparison rating

\begin{tabular}{|c|c|c|}
\hline $\begin{array}{l}\text { Degree of } \\
\text { importance }\end{array}$ & $\begin{array}{l}\text { Level of } \\
\text { preference }\end{array}$ & Description \\
\hline 1 & Equal & Two criteria contribute equally to the goal \\
\hline 2 & Weak & \\
\hline 3 & Moderate & $\begin{array}{l}\text { Judgment slightly to moderately in favor of the one criteria against } \\
\text { another }\end{array}$ \\
\hline 4 & $\begin{array}{l}\text { Moderate } \\
\text { plus }\end{array}$ & \\
\hline 5 & Strong & Judgment strongly in favor of the one criteria against another \\
\hline 6 & Strong plus & \\
\hline 7 & Very strong & $\begin{array}{l}\text { Judgment strongly in favor of the one criteria against another and its } \\
\text { dominance is confirmed in practice }\end{array}$ \\
\hline 8 & $\begin{array}{l}\text { Very, very } \\
\text { strong }\end{array}$ & \\
\hline 9 & Extreme & $\begin{array}{l}\text { Judgment highest degree possible in favor of the one criteria against } \\
\text { another }\end{array}$ \\
\hline
\end{tabular}

This study was confirmed by the Ethics Committee of the National Institute for Medical Research Development (NIMAD), Tehran, Iran (IR.NIMAD.REC.1398.337).

\section{Results}

In this study, we conducted 30 semi-structured interviews to investigate policy recommendations to improve the insurance coverage for physiotherapy services in Iran. Then, AHP approach was used to prioritize the recommendations in accordance with the six criteria (effectiveness, acceptability, cost, fairness, feasibility, and time).

Through the qualitative study, participants expressed a number of policy recommendations. These proposed recommendations for each component of conceptual framework are shown in Table 3. Stewardship, including inter-sectoral leadership and intra-sectoral governance, was highlighted by most of participants. They proposed several options to improve this domain such as moving to united stewardship, informing the policy-makers about physiotherapy services and their effects, participating the rehabilitation experts in decision- and policy-making process, etc. (Table 3(a)). Improving collection of funds or revenue collection is another main component of financing process that participants especially policy-makers and faculty members recommended various policy solutions for it such as value-added tax on luxury goods and services, considering higher insurance contributions (premiums) for families without any child, earmarking 
the allocated resources, etc. (Table 3(b)). Other policy recommendations in order to improve the pooling of funds, purchasing, and benefit package are shown in Table 3(c), Table 3(d), and Table 3(e), respectively. 
Table 3

Recommendations to improve the insurance coverage for physiotherapy services

\section{ID Recommendation}

(a) Stewardship

$1 \quad$ Moving to united stewardship

2 Informing the policy-makers about physiotherapy services and their effects

3 Participating the rehabilitation experts in decision- and policy-making process

$4 \quad$ Improving health technology assessment (HTA) process

$5 \quad$ Facilitating the interdisciplinary collaborations

6 Conducting regular supervision and accreditation

7 Strengthening referral system

8 Conducting comprehensive need assessments

9 Establishing accurate information system

10 Transparent prioritizing and rationing

11 Promoting the interaction level between scientific associations and insurers

(b) Collection of funds

$1 \quad$ Value-added tax on luxury goods and services

2 Tax on chemical and toxic industries

3 Tax on harmful substances such as tobacco, sugar, etc.

$4 \quad$ Considering higher insurance contributions for families without any child

5 Obligating the complementary health insurance for employed groups

6 Promoting the rehabilitation funding proportion from public budget

7 Earmarking the allocated resources

8 Considering a separate premium for rehabilitation services (including physiotherapy)

(c) Pooling of funds

1 Moving the allocated resources to insurance (third party) mechanism

2 Integrating the insurance funds

3 Cross-subsiding across different groups at national level

$4 \quad$ Using individual medical saving accounts

5 Consolidation the small insurance funds 


\begin{tabular}{|ll|}
\hline ID & Recommendation \\
\hline (d) Purchasing \\
\hline 1 & Separation between provider and purchaser \\
\hline 2 & Using strategic purchasing \\
\hline 3 & Considering quality indicators in purchasing process \\
\hline 5 & Limiting the induced demands by payment and punishing mechanisms \\
\hline 6 & Using rehabilitation experts in purchasing process \\
\hline 7 & Correcting the tariffs based on economic situation \\
\hline 8 & Reducing the co-payment rates \\
\hline 9 & Using capitation mechanism to control the expenditures \\
\hline$(e)$ & Benefit package \\
\hline 1 & Considering the cost-effectiveness interventions \\
\hline 2 & Considering the preventive interventions \\
\hline 3 & Considering needed interventions in golden time treatment after diseases \\
\hline 4 & Considering the inpatient interventions \\
\hline 5 & Coverage of physiotherapy services required for children up to the age of six \\
\hline 6 & Coverage of physiotherapy services up to age of 18 \\
\hline
\end{tabular}

Regarding the AHP session, the findings of the pairwise comparisons of the six criteria are presented in Table 4. As shown in the Table, the relative importance of criteria includes feasibility with a ratio of 0.258 , which had the highest importance; acceptability with a ratio of 0.178 ; fairness with a ratio of 0.171 ; cost with a ratio of 0.138 ; effectiveness with a ratio of 0.131 ; and finally, time with a ratio of 0.124 , which had the lowest importance. In the pairwise comparison of the six criteria compared with the goal, the inconsistency index was 0.09 . 
Table 4

Matrix of pairwise comparisons

\begin{tabular}{|llllllll|}
\hline $\begin{array}{l}\text { Main } \\
\text { criterion }\end{array}$ & Feasibility & Acceptability & Fairness & Cost & Effectiveness & Time & $\begin{array}{l}\text { Relative } \\
\text { importance }\end{array}$ \\
\hline Feasibility & 1 & 1 & 2 & 2 & 3 & 2 & 0.258 \\
\hline Acceptability & 1 & 1 & $1 / 2$ & 1 & 2 & 2 & 0.178 \\
\hline Fairness & $1 / 2$ & 2 & 1 & 2 & 1 & $1 / 2$ & 0.171 \\
\hline Cost & $1 / 2$ & 1 & $1 / 2$ & 1 & 1 & 2 & 0.138 \\
\hline Effectiveness & $1 / 3$ & $1 / 2$ & 1 & 1 & 1 & 2 & 0.131 \\
\hline Time & $1 / 2$ & $1 / 2$ & 2 & $1 / 2$ & $1 / 2$ & 1 & 0.124 \\
\hline
\end{tabular}

Then, policy recommendations of each component were paired compared in accordance with the six criteria. Supplemental Fig. 2 presents the prioritization of recommendations for stewardship based on each criterion. According to the Fig. 3, informing the policy-makers about physiotherapy services and their effects (0.128), had the highest priority and followed by participating the rehabilitation experts in decisionand policy-making process $(0.115)$, promoting the interaction level between scientific associations and insurers (0.098), conducting regular supervision and accreditation (0.098), strengthening referral system (0.095), establishing accurate information system (0.084), conducting comprehensive need assessments (0.080), transparent prioritizing and rationing $(0.080)$, improving health technology assessment (HTA) process $(0.078)$, facilitating the interdisciplinary collaborations $(0.073)$, and finally, moving to united stewardship (0.071) had the lowest priority. Performance sensitivity analysis of these recommendations also is demonstrated in Fig. 3.

Prioritization of policy recommendations for collection of funds based on six criteria are shown in Supplemental Fig. 3. Also, Fig. 4 shows the performance sensitivity analysis and overall prioritization of recommendations in accordance with criteria for this component. As presented, value-added tax on luxury goods and services (0.158), tax on harmful substances such as tobacco, sugar, etc. (0.144), considering a separate premium for rehabilitation services (including physiotherapy) (0.140), earmarking the allocated resources (0.140), tax on chemical and toxic industries (0.135), considering higher insurance contributions for families without any child (0.127), obligating the complementary health insurance for employed groups (0.086), and promoting the rehabilitation funding proportion from public budget (0.069), were ranked from highest to lowest.

Prioritization of policy recommendations for pooling of funds based on six criteria are also demonstrated in Supplemental Fig. 4. As the overall findings are shown in Fig. 5, moving the allocated resources to insurance (third party) mechanism (0.294), had the highest priority and followed by cross-subsiding across different groups at national level (0.199), integrating the insurance funds (0.180), consolidation the small insurance funds (0.173), and finally, using individual medical saving accounts $(0.154)$, which had the 
lowest priority. In addition, you can see the performance sensitivity analysis based on the each criterion in Fig. 5.

Purchasing was other component of financing which a number of policy recommendations are provided to improve it. Supplemental Fig. 5 is shown the prioritization of obtained alternatives based on the six criteria. Furthermore, the performance sensitivity analysis and overall prioritization are demonstrated in Fig. 6. As shown, using strategic purchasing (0.162), correcting the tariffs based on economic situation (0.130), and considering quality indicators in purchasing process (0.127), were the top three priorities. In addition, limiting the induced demands by payment and punishing mechanisms $(0.111)$, using rehabilitation experts in purchasing process (0.104), considering performance- or outcome-based payment system (0.097), reducing the co-payment rates (0.093), and using capitation mechanism to control the expenditures (0.093), were ranked from four to eight. Finally, separation between provider and purchaser (0.084) had the lowest priority, however, it was one of the top priorities according to effectiveness.

The last component was the benefit package which its policy recommendations are prioritize based on each criterion (Supplemental Fig. 6). As other components, the performance sensitivity analysis and overall prioritization are described in Fig. 7. The analyses are revealed that considering the preventive interventions (0.207) had the first rank. This was a notable finding. Further, coverage of physiotherapy services up to age of 18 (0.195) and considering the needed interventions in golden time treatment after diseases (such as stroke) (0.188) were the second and third priorities. Finally, coverage of physiotherapy services required for children up to the age of six (0.162), considering the inpatient (0.147) and cost-effectiveness interventions (0.101), were other alternatives to improve the benefit package of insurance institutes.

\section{Discussion}

This study aimed to obtain and prioritize the policy recommendations to improve the insurance coverage for physiotherapy services in Iran. In the first phase, a diverse group of experts were involved to ensure a range of knowledge, attributes, and skills. Additionally, in the second phase, obtained recommendations were prioritize to highlight theirs practicability. In accordance with the conceptual framework components (stewardship, collection of funds, pooling of funds, purchasing, and benefit package), various policy recommendations are proposed and prioritized.

\section{Stewardship}

As a result, promoting the awareness of policy-makers may be a considerable policy recommendation to strength the financing stewardship. Indeed, most of health policy-makers are unaware of these services in Iran [9]. Furthermore, participation of patients and rehabilitation experts in policy processes is another option which has noted by recent evidence [26]. Unfortunately, disabled persons and other relevant groups have no enough power or influence to involve in decision- and policy-making processes in Iran [21]. Collaboration between scientific associations and health insurers can be another alternative to improve the insurance coverage of physiotherapy service. Scientific associations can provide a list of interventions which have lower costs and prevent many future complications. Furthermore, improving the health 
technology assessment (HTA) can play important role in this domain [27]. Even so, weakness in HTA process is one of the common problems in Iranian health care system [28]. Therefore, further economic evaluation (cost-effectiveness, cost-utility, and cost-benefit) should be conducted to demonstrate the effects and costs of physiotherapy services. Another proposed policy was improving the supervision and accreditation system. Unfortunately, in Iran like many other countries, there is no transparent and regular supervision system in health-related rehabilitation sector including physiotherapy [21]. In addition, lack of comprehensive accreditation is another feature of physiotherapy sector in Iran [29]. Despite this fact, providers' accreditation is a standard tool to assure the quality of services that is very important for insurers [30]. Therefore, develop the effective supervision and accreditation is necessary for physiotherapy sector. Evidence-based priority setting and rationing in health system was a proposed recommendation which can promote the physiotherapy status in benefit packages. However, current health care rationing does not follow any convinced rationale [31, 32]. Fragmentation in stewardship of financing is always shown as one of significant barriers for universal insurance coverage of health services including physiotherapy in Iran. Consequently, moving to united stewardship may be a potential policy recommendation [14]. Surprisingly, although our findings were prioritized united stewardship as one of the best alternatives based on effectiveness criterion, it had not high priority based on other criteria. Indeed, in accordance with the current context of Iran, this policy cannot be a feasible and acceptable recommendation.

\section{Collection of funds}

In regard to the collection of funds, several recommendation were presented by this study. WHO always has focused on innovative ways such as tax on chemical and toxic industries, value-added tax on luxury goods and services, and tax on harmful substances such as tobacco, sugar, etc. $[15,16]$ which in accordance with our findings. These policy options can provide new funding resources for insurance coverage of physiotherapy services. Earmarked tax, also known as hypothecated tax, is developed for a particular plans [15]. Most of the policy-makers were believed that earmarked tax can be a considerable fund source for rehabilitation services such as physiotherapy. Ministries of health are often favoring these tax because they secure financing, especially for health promotion and prevention. Furthermore, participants highlighted that approximately all allocated funds for physiotherapy and other rehabilitation services, should be earmarked. Based on the 4th Economic, Social, and Cultural Development Plan Act (Article 92) in Iran, 10\% of third-part insurance must be allocated to cover medical expenditures of traffic injuries [33]. Therefore, as many traffic injuries require physiotherapy services, a part of this fund can also earmarked for physiotherapy services. Considering higher insurance contributions for families without any child was another notable policy recommendation for collection of funds. Policy-makers were believed that persons without any child need more rehabilitation serviced such as physiotherapy. Therefore, this premium can provide expedient financial resources.

\section{Pooling of funds}

Pre-payment is the only way to reduce the direct payments and also financial hardships. In this approach, premiums were collected through insurance mechanisms, and risk-sharing and risk-pooling were conducted [34]. In agreement with evidence, our findings concluded that moving the allocated resources for 
rehabilitation services to insurance (third party) mechanisms is essential. However, the current funding for rehabilitation services is highly dispersed and each organization receives a separate budget [21].

Additionally, using effective third-part mechanisms at national level, facilitate the cross-subsidization. This policy is possible where multiple funds and different insured groups (poor and rich, young and old) be available [15]. Nevertheless. Fragmented funds is one of the key challenges of health care financing in Iran which works against equity goals [34]. Therefore, integrating the insurance funds or consolidation the small insurance funds can be policy options to improve this situation. Participants were discussed that current fragmentation has reduced efficiency and capacity for cross-subsidization, as mentioned in previous evidence $[35,36]$.

\section{Purchasing}

In regard to the purchasing, several policy recommendation were proposed. Based on the prioritization, using strategic purchasing had the highest rank. This result is consistent with the relevant evidence [37, 38]. However, a major proportion of health care services such as physiotherapy, are provided by financing funds. Indeed, there is no actual a purchaser-provider split. Therefore, considering the strategic purchasing principals, such as focus on quality indicators in purchasing process and using performance- or outcomebased payment system, can be one of the best alternatives to improve the insurance status of physiotherapy services. Furthermore, participants had believed that current tariffs are not real and must be corrected in accordance with the economic changes. Recent studies also confirmed this problem in financing of Iranian health care system [39, 40]. Therefore, setting real tariffs will also increase the utilization, in addition to preventing informal payments.

\section{Benefit package}

In Iran, basic and complementary health benefit packages are developed by High Council of Health Insurance ( $\mathrm{HCHI}$ ) and all health insurance schemes must follow it [39]. Unfortunately, health-related rehabilitation services including in physiotherapy are not well considered. As a result, the number of interventions and the depth of coverage of physiotherapy services are very poor. Despite this, our study recommended notable and remarkable policy options to improve this situation. Considering the preventive physiotherapy interventions can be attractive option for decision- and policy-makers. In fact, many

physiotherapy services have preventive effects, which can prevent expensive interventions such as surgery in future $[17,19,41]$. Additionally, some physiotherapy interventions if prescribed until the age of eighteen, can be very effective $[42,43]$. Therefore, considering these interventions and also cost-effectiveness strategies can be included in benefit packages [44]. During the interviews, providers and faculty-members described the importance of physiotherapy after stroke and trauma. As shown by evidence, if physiotherapy interventions are provided in golden time (6-month after stroke or 12-month after trauma injury), many side effects are prevented $[18,45]$. Therefore, these services may be other potential interventions to be considered by health insurers.

\section{Study Strengths And Limitations}


The selected face-to-face interview sites were mainly be in metropolitan areas which may limit our findings. However, we strived to consider other experts using Skype and telephone. Also, some participants especially health policy-makers had no interest to participate. Nevertheless, a broad and diverse sample of participants have been selected to reduce this limitation. Accurate design and methodology was the strong feature of our study.

\section{Conclusions}

In this study, several policy recommendations were proposed and prioritized to improve the insurance coverage of physiotherapy services in Iran. Hopefully, the findings of this study, will be provided a favorable ground to improve the insurance coverage for physiotherapy services, and decision- and policy-makers can place these recommendations at their agenda settings in the health sector to protect the health status of population, especially disabled groups.

Word counts: 3410

\section{Abbreviations}

MSK

Musculoskeletal; YLDs:Years lived with disability; DALYs:Disability-adjusted life years; LBP:Low-Back Pain; OA):Osteoarthritis; AR:Arthritis Rheumatoid; EMR:Eastern Mediterranean Region; OOP:Out-of-pocket; CEs:Catastrophic expenditures; WHO:World Health Organization; UHC:Universal health coverage; SSO:Social Security Organization; IHIO:Iran Health Insurance Organization; AFSSO:Armed Forces Social Security Organization; AHP:Analytical Hierarchy Process; MCDM:Multi-criteria decision making; HCHI:High Council of Health Insurance.

\section{Declarations}

\section{Acknowledgement}

Not applicable

\section{Authors' contributions}

SSH and STH contributed to the conception and design of the study. SSH conducted the interviews, and STH and KBL were co-moderators. SSH conducted most of the analysis, which STH, KBL, and LZ discussed regularly. SSH wrote the initial draft, and STH, KBL, and LZ contributed to manuscript revisions. All authors read and confirmed the final manuscript.

\section{Funding}

This work was supported by the National Institute for Medical Research Development (NIMAD), Tehran, Iran (No. 987627). 
Availability of data and materials

The data collected and analyzed during the study are available from the corresponding author on reasonable request.

Ethics approval and consent to participate

This study was confirmed by the Ethics Committee of the National Institute for Medical Research Development (NIMAD), Tehran, Iran (IR.NIMAD.REC.1398.337). All participants were provided written consent form, and then provided verbal consent prior to interview sessions.

Consent for publication

Not applicable

Competing interests

The authors declare that they have no competing interest to share.

\section{References}

1. Organization WH: WHO global disability action plan 2014-2021: Better health for all people with disability: World Health Organization; 2015.

2. Sebbag E, Felten R, Sagez F, Sibilia J, Devilliers H, Arnaud L: The world-wide burden of musculoskeletal diseases: a systematic analysis of the World Health Organization Burden of Diseases Database. Ann Rheum Dis 2019, 78(6):844-848.

3. Feigin VL, Nichols E, Alam T, Bannick MS, Beghi E, Blake N, Culpepper WJ, Dorsey ER, Elbaz A, Ellenbogen RG: Global, regional, and national burden of neurological disorders, 1990-2016: a systematic analysis for the Global Burden of Disease Study 2016. Lancet Neurol 2019, 18(5):459-480.

4. Moradi-Lakeh M, Forouzanfar MH, Vollset SE, El Bcheraoui C, Daoud F, Afshin A, Charara R, Khalil I, Higashi H, El Razek MMA: Burden of musculoskeletal disorders in the Eastern Mediterranean Region, 1990-2013: findings from the Global Burden of Disease Study 2013. Ann Rheum Dis 2017, 76(8):1365-1373.

5. Heinemann AW, Feuerstein M, Frontera WR, Gard SA, Kaminsky LA, Negrini S, Richards LG, Vallée C: Rehabilitation Is a Global Health Priority. In.: Springer; 2020.

6. Shirazikhah M, Mirabzadeh A, Sajadi H, Joghataei MT, Biglarian A, Mousavi T, Shahboulaghi FM: National survey of availability of physical rehabilitation services in Iran: A mixed methods study. Electron Physician 2017, 9(11):5778.

7. Farzadfard MT, Sheikh Andalibi MS, Thrift AG, Morovatdar N, Stranges S, Amiri A, Kapral MK, Behrouz $\mathrm{R}$, Juibary AG, Mokhber N: Long-term disability after stroke in Iran: Evidence from the Mashhad Stroke Incidence Study. Int J Stroke 2019, 14(1):44-47. 
8. Foroutaghe MD, Moghaddam AM, Fakoor V: Time trends in gender-specific incidence rates of road traffic injuries in Iran. PloS one 2019, 14(5).

9. Soltani S, Takian A, Sari AA, Majdzadeh R, Kamali M: Cultural barriers in access to healthcare services for people with disability in Iran: A qualitative study. Med J Islam Repub Iran 2017, 31:51.

10. Zarei E, Nikkhah A, Pouragha B: Utilization and out of pocket (OOP) payment for physiotherapy services in public hospitals of Shahid Beheshti University of Medical Sciences. Med J Islam Repub Iran 2018, 32:19.

11. Reich MR, Harris J, Ikegami N, Maeda A, Cashin C, Araujo EC, Takemi K, Evans TG: Moving towards universal health coverage: lessons from 11 country studies. The Lancet 2016, 387(10020):811-816.

12. Organization WH: Rehabilitation in health systems: guide for action. 2019.

13. Stucki G, Bickenbach J, Gutenbrunner C, Melvin J: Rehabilitation: the health strategy of the 21st century. J Rehabil Med 2018, 50(4):309-316.

14. Mehrolhassani M, Najafi B, Yazdi Feyzabadi V, Abolhallaje M, Ramezanian M, Dehnavieh R, Emami M: A review of the health financing policies towards universal health coverage in Iran. Iran J Epidemiol 2017, 12:74-84.

15. Evans DB, Etienne C: Health systems financing and the path to universal coverage. In.: SciELO Public Health; 2010.

16. Kutzin $\mathrm{J}$ : Health financing for universal coverage and health system performance: concepts and implications for policy. Bull World Health Org 2013, 91:602-611.

17. Wang M-Y, Pan L, Hu X-J: Chest physiotherapy for the prevention of ventilator-associated pneumonia: A meta-analysis. Am J Infect Control 2019, 47(7):755-760.

18. Shahabi S, Shabaninejad H, Kamali M, Jalali M, Ahmadi Teymourlouy A: The effects of ankle-foot orthoses on walking speed in patients with stroke: a systematic review and meta-analysis of randomized controlled trials. Clin Rehabil 2019:0269215519887784.

19. Boden I, Skinner EH, Browning L, Reeve J, Anderson L, Hill C, Robertson IK, Story D, Denehy L: Preoperative physiotherapy for the prevention of respiratory complications after upper abdominal surgery: pragmatic, double blinded, multicentre randomised controlled trial. BMJ 2018, 360:j5916.

20. Henderson KG, Wallis JA, Snowdon DA: Active physiotherapy interventions following total knee arthroplasty in the hospital and inpatient rehabilitation settings: a systematic review and metaanalysis. Physiotherapy 2018, 104(1):25-35.

21. Abdi K, Arab M, Khankeh HR, Kamali M, Rashidian A, Farahani FK, Shemshadi H: Challenges in providing rehabilitation services for people with disabilities in Iran: A qualitative study. J Adv Med Med Res 2016:1-11.

22. Saaty TL: Decision making with the analytic hierarchy process. Int J Serv Sci 2008, 1(1):83-98.

23. Terwindt F, Rajan D, Soucat A: Priority-setting for national health policies, strategies and plans. Strategizing national health in the 21st century: a handbook 2016, 71.

24. Saaty TL, Özdemir MS: How many judges should there be in a group? Ann Data Sci 2014, 1(3-4):359368. 
25. Boroushaki S, Malczewski J: Implementing an extension of the analytical hierarchy process using ordered weighted averaging operators with fuzzy quantifiers in ArcGIS. Comput Geosci 2008, 34(4):399-410.

26. McVeigh J, MacLachlan M, Gilmore B, McClean C, Eide AH, Mannan H, Geiser P, Duttine A, Mji G, McAuliffe E: Promoting good policy for leadership and governance of health related rehabilitation: a realist synthesis. Global Health 2016, 12(1):49.

27. Hollingworth S, Gyansa-Lutterodt M, Dsane-Selby L, Nonvignon J, Lopert R, Gad M, Ruiz F, Tunis S, Chalkidou K: Implementing health technology assessment in Ghana to support universal health coverage: building relationships that focus on people, policy, and process. Int $J$ Technol Assess Health Care 2019:1-4.

28. Olyaeemanesh A, Majdzadeh R: Health technology assessment: A necessity in post-sanctions Iran while implementing the health transformation plan. Med J Islam Repub Iran 2016, 30:436.

29. Nekoei-Moghadam M, Amiresmaili M, Iranemansh M, Iranmanesh M: Hospital accreditation in Iran: A qualitative case study of Kerman hospitals. Int J Health Plann Manage 2018, 33(2):426-433.

30. Lamptey AA, Nsiah-Boateng E, Agyemang SA, Aikins M: National health insurance accreditation pattern among private healthcare providers in Ghana. Arch Public Health 2017, 75(1):36.

31. Rahmani K, Rezayatmand R, Sadeghpour N, Nikaeen M, Arabi S, Molavi Taleghani Y. Policy-making for Rationing in the Healthcare System: A review to provide suggestions for Iran. Manage Strat Health Syst 2018 10;3(3):249-62.

32. Yaghoubi M, Bahadori M, Ravangard R: Factors Affecting Income Inequity Among Healthcare Workers in Iran: A Commentary. Shiraz E Med J 2019, 20(1).

33. Aderyani MR, Naeeni MS, Musavi F, Salehnia E, Dehghani A, Barati M, Babaeeian K: Exploring the status of executing traffic accidents insurance (article 92 of Islamic Republic of Iran's fourth budget plan) according to the Financial Scale of Special Incomes and Non-Settled Traffic Accidents Files at Kashani Hospital of Isfahan. Iran J Med Law 2016, 9(35):185-204.

34. Bazyar M, Rashidian A, Kane S, Mahdavi MRV, Sari AA, Doshmangir L: Policy options to reduce fragmentation in the pooling of health insurance funds in Iran. Int $J$ Health Policy Manag 2016, 5(4):253.

35. Chu A, Kwon S, Cowley P: Health financing reforms for moving towards universal health coverage in the western pacific region. Health Syst Reform 2019, 5(1):32-47.

36. Mathauer I, Torres LV, Kutzin J, Jakab M, Hanson K: Pooling financial resources for universal health coverage: options for reform. Bull World Health Org 2020, 98(2):132.

37. Paul E, Ridde V, Brown G: Strategic purchasing for health: conceptual and implementation challenges in low-and middle-income countries. 2019.

38. Witter S, Chirwa Y, Chandiwana P, Munyati S, Pepukai M, Bertone MP, Banda S: Results-based financing as a strategic purchasing intervention: some progress but much further to go in Zimbabwe? BMC Health Serv Res 2020. 
39. Bazyar M, Rashidian A, Sakha MA, Mahdavi MRV, Doshmangir L: Combining health insurance funds in a fragmented context: what kind of challenges should be considered? BMC Health Serv Res 2020, 20(1):1-14.

40. Doshmangir L, Bazyar M, Najafi B, Haghparast-Bidgoli H: Health financing consequences of implementing health transformation plan in Iran: achievements and challenges. Int $\mathrm{J}$ Health Policy Manag 2019, 8(6):384.

41. Steffens D, Maher CG, Pereira LS, Stevens ML, Oliveira VC, Chapple M, Teixeira-Salmela LF, Hancock MJ: Prevention of low back pain: a systematic review and meta-analysis. JAMA Intern Med 2016, 176(2):199-208.

42. Chaves GS, Freitas DA, Santino TA, Nogueira PAM, Fregonezi GA, Mendonca KM: Chest physiotherapy for pneumonia in children. Cochrane Database Syst Rev 2019(1).

43. Sebban S, Evenou D, Jung C, Fausser C, Jeulin S, Durand S, Bibal M, Geninasca V, Saux M, Leclerc M: Symptomatic Effects of Chest Physiotherapy with Increased Exhalation Technique in Outpatient Care for Infant Bronchiolitis: A Multicentre, Randomised, Controlled Study. Bronkilib 2. J Clin Res Med 2019, 2(4):1.

44. Shahabi S, Rezapour A, Arabloo J: Economic evaluations of physical rehabilitation interventions in older adults with hip and/or knee osteoarthritis: a systematic review. Eur J Physiother 2019:1-11.

45. Dubey L, Karthikbabu S, Mohan D: Effects of pelvic stability training on movement control, hip muscles strength, walking speed and daily activities after stroke: a randomized controlled trial. Ann Neurosci 2018, 25(2):80-89.

\section{Figures}




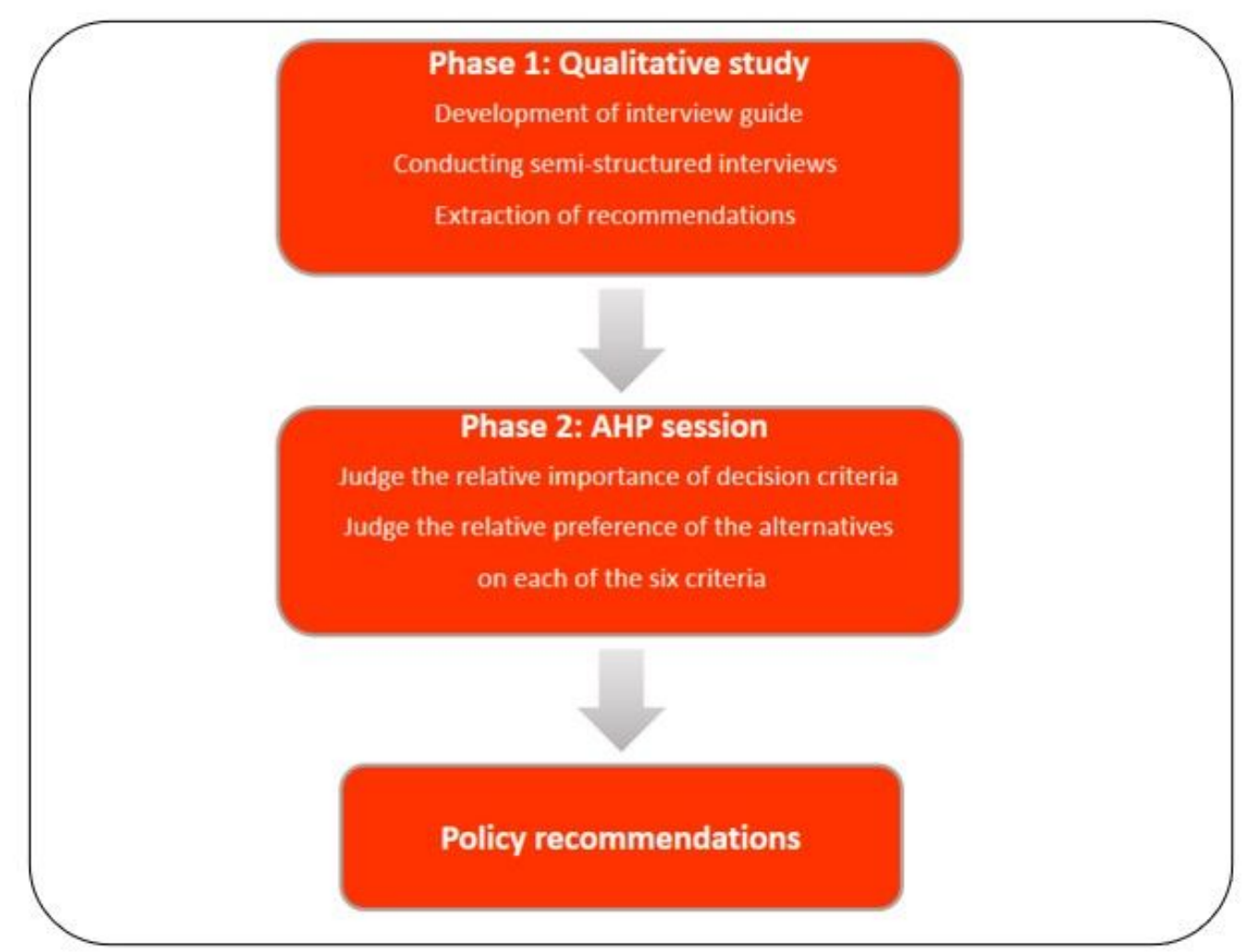

Figure 1 Overview of study methods

\section{Figure 1}

Overview of study methods

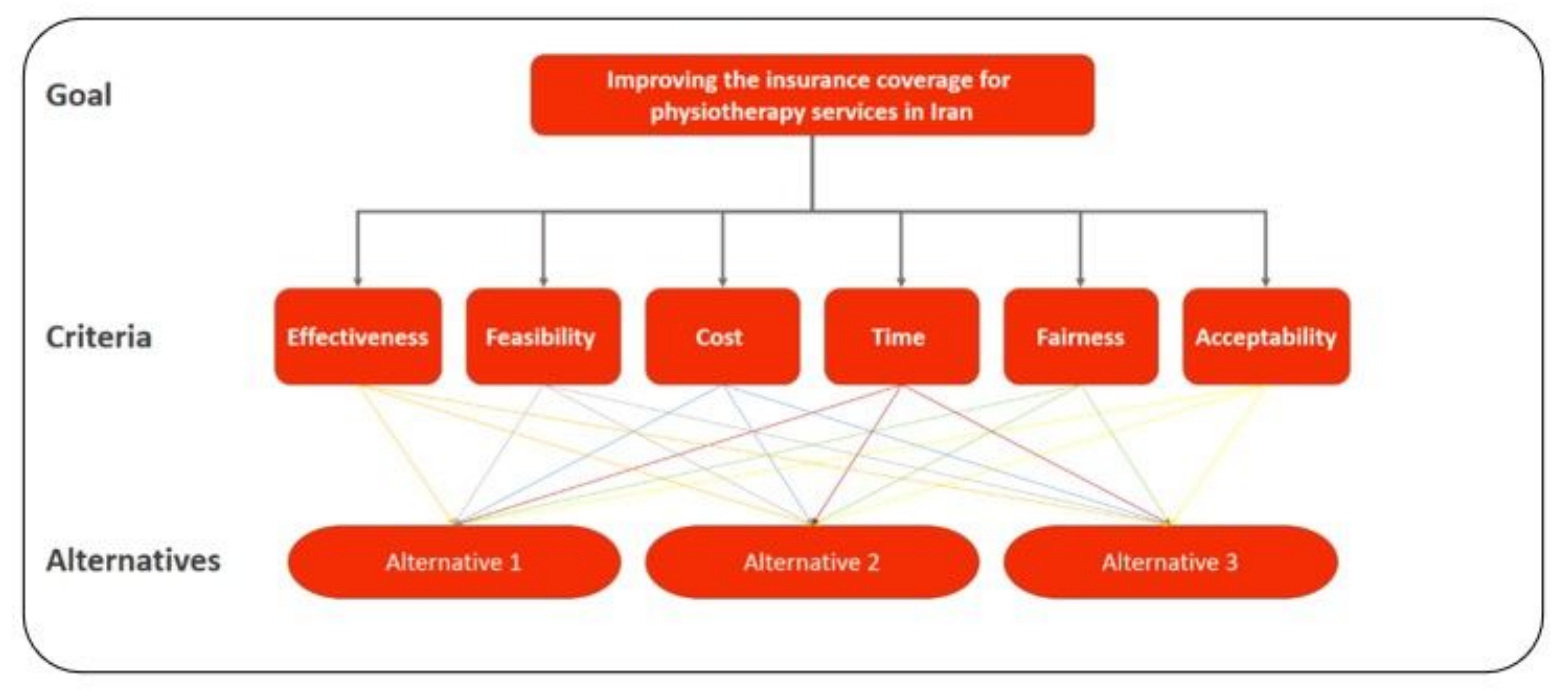

Figure 2 AHP hierarchy 
Figure 2

AHP hierarchy

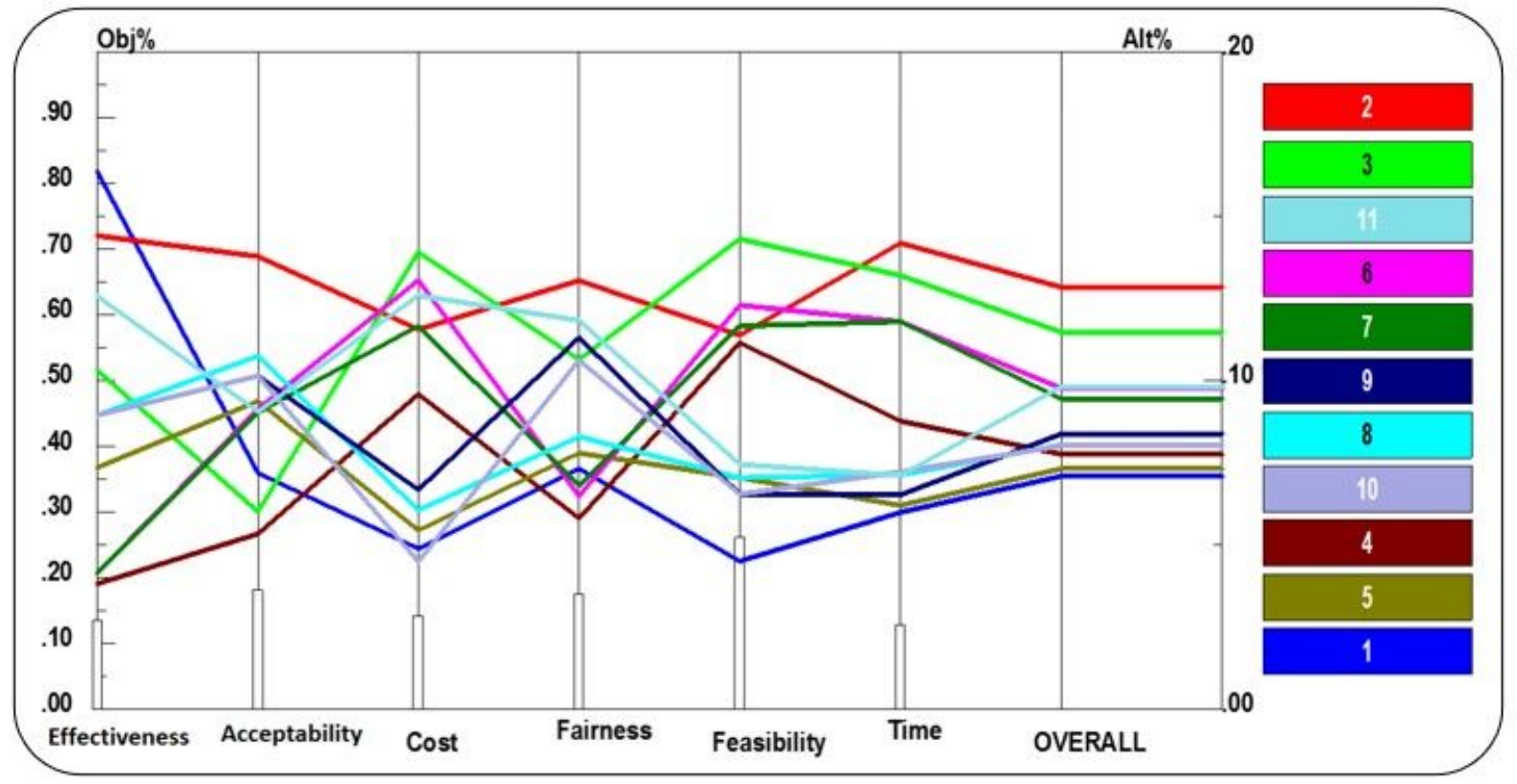

Figure 3 Performance sensitivity analysis of policy recommendations for stewardship

\section{Figure 3}

Performance sensitivity analysis of policy recommendations for stewardship 


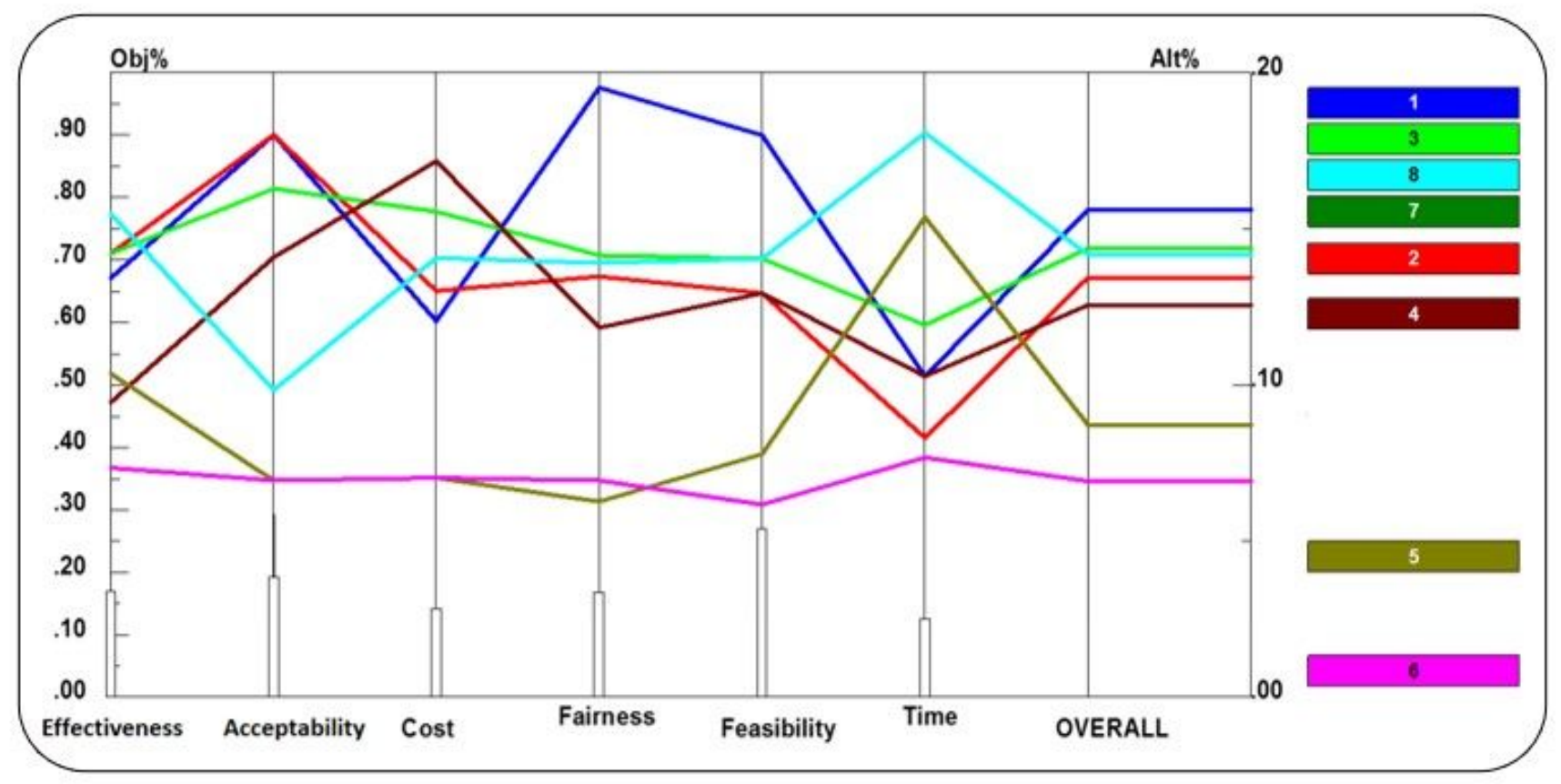

Figure 4 Performance sensitivity analysis of policy recommendations for collection of funds

\section{Figure 4}

Performance sensitivity analysis of policy recommendations for collection of funds

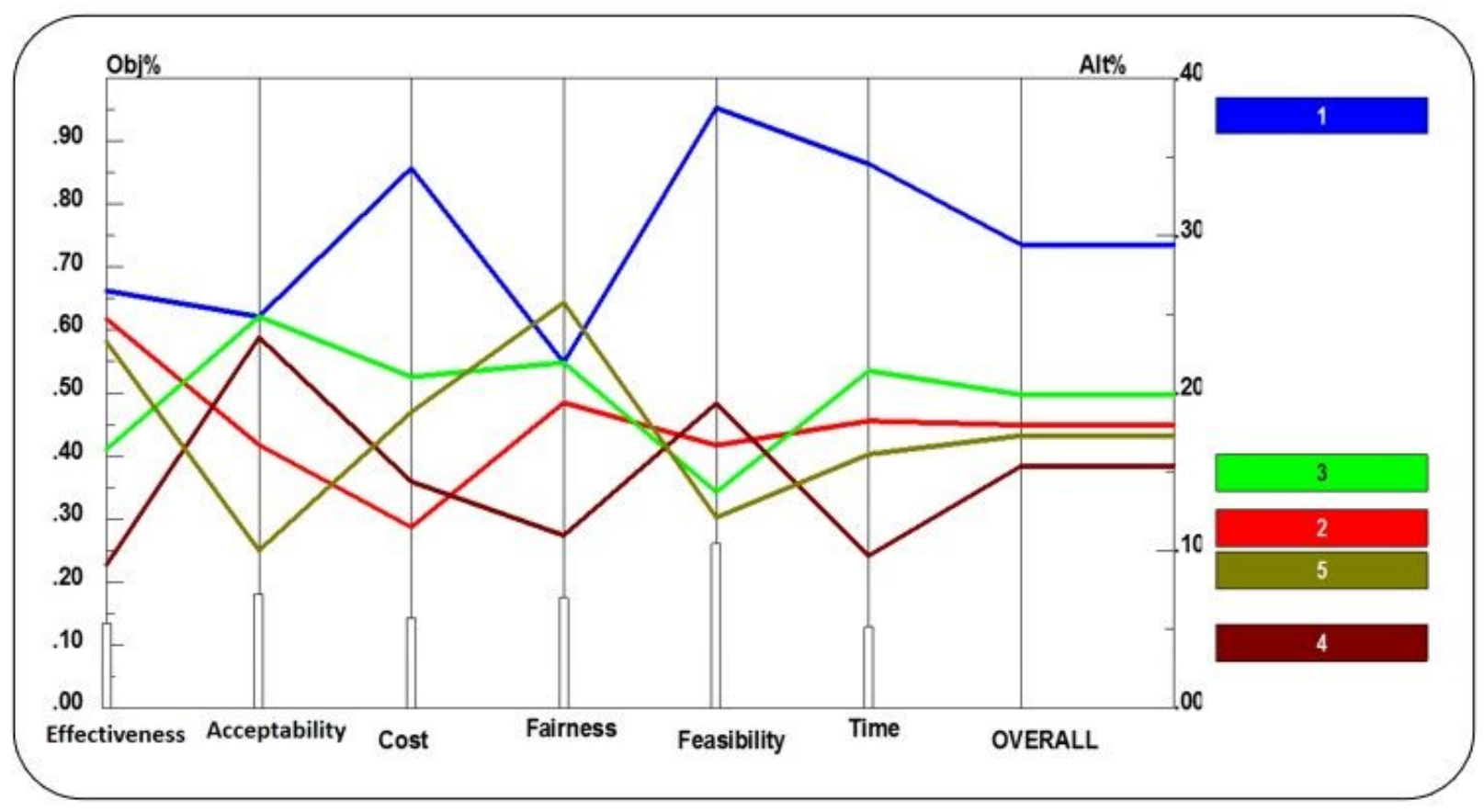

Figure 5 Performance sensitivity analysis of policy recommendations for pooling of funds

Figure 5 


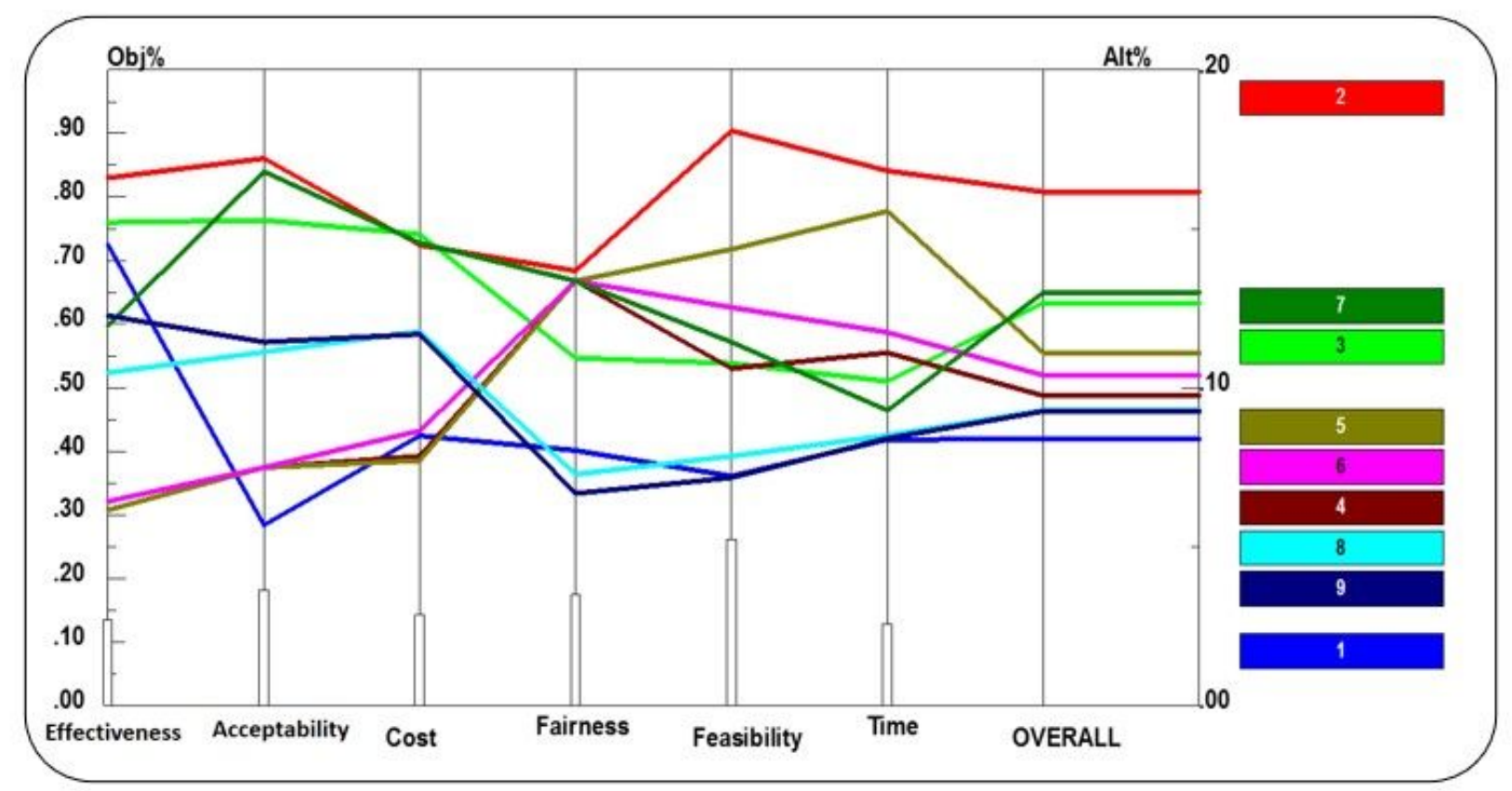

Figure 6 Performance sensitivity analysis of policy recommendations for purchasing

\section{Figure 6}

Performance sensitivity analysis of policy recommendations for purchasing

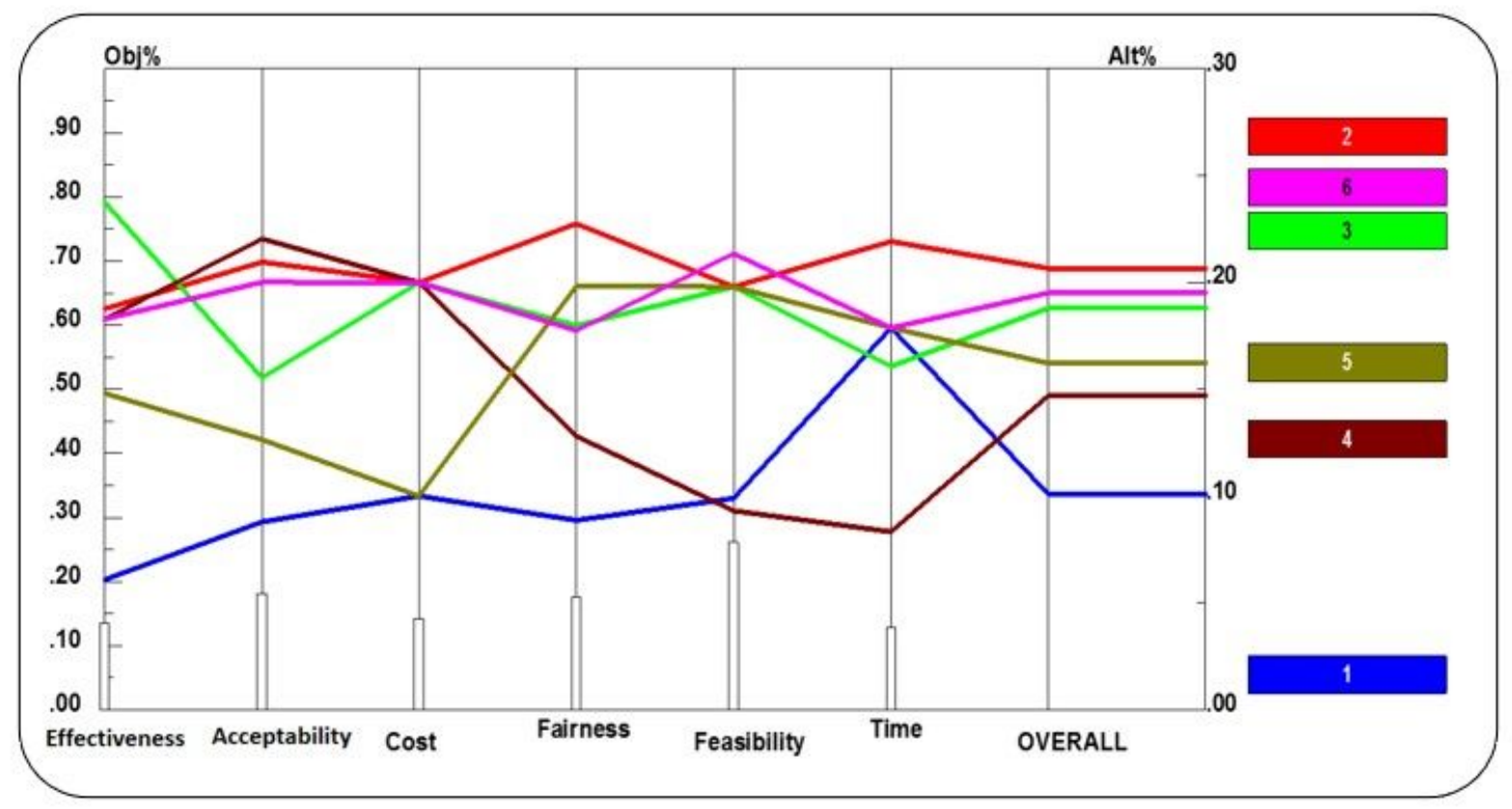

Figure 7 Performance sensitivity analysis of policy recommendations for benefit package 
Figure 7

Performance sensitivity analysis of policy recommendations for benefit package

\section{Supplementary Files}

This is a list of supplementary files associated with this preprint. Click to download.

- Supplemental.docx 